\title{
BIOLIXIVIAÇÃO: UMA AVALIAÇÃO DAS INOVAÇÕES TECNOLÓGICAS NA BIOMINERAÇÃO DE MINERAIS SULFETADOS NO PERÍODO DE I99I A 2015
}

Ellen Cristine Giese '

\section{Resumo}

O desenvolvimento de inovações tecnológicas nos processos de biolixiviação tem sido constante, principalmente, pelo fato dos processos biohidrometalúrgicos oferecerem vantagens frente às plantas convencionais, v. g., a diminuição dos custos operacionais e de geração de resíduos. O objetivo deste trabalho foi avaliar o perfil das competências tecnológicas relacionadas à este processo através do estudo das patentes depositadas na base de dados da Organização Mundial de Propriedade Intelectual (OMPI) nos últimos 25 anos. Observou-se que, entre os anos de I99 I e 20I5, cerca de 328 patentes foram depositadas na Patentscope, destacando-se a China e EUA que somados detém igualmente $44 \%$ dos registros. A partir dos resultados obtidos nesta pesquisa, foi traçado um paralelo entre os depósitos de patentes e a economia mineral. A análise dos dados obtidos permitiu descrever as tecnologias preferencialmente protegidas dos processos de biolixiviação. Palavras-chave: Bio-hidrometalurgia; Biolixiviação; Patentes.

\section{BIOLEACHING: AN EVALUATION OF TECHNOLOGICAL INNOVATIONS ON THE SULPHIDE MINERALS IN THE PERIOD OF I99| TO 2015}

\begin{abstract}
The development of technological innovations in bioleaching has been constant, especially, the use of these biohydrometallurgical processes offer advantages over conventional plants, such as lower operating costs and waste generation. The objective of this study was to evaluate the potential of technological competence related to this process through the analysis of patents in the database of the World Intellectual Property Organization (WIPO) in the last 25 years. It was observed that between the years 199I and 2015, about 328 patents were filed in Patenstcope, especially China and USA which added also holds $44 \%$ of the documents. From obtained results, it has drawn a parallel between the patent deposits and the mineral economy. The analysis of the data allowed describing the technologies protected preferably of bioleaching processes.
\end{abstract}

Keywords: Biohydrometallurgy; Bioleaching; Patents.

\section{INTRODUÇÃO}

A cadeia produtiva da metalurgia de minerais não-ferrosos, de maneira geral, envolve processos de concentração (moagem, britagem, flotação e secagem), seguido de pirometalurgia ou hidrometalurgia $[1,2]$. Todavia, estes processos convencionais não se apresentam economicamente viáveis para a extração de metais a partir de minérios oxidados ou minérios de baixo teor notadamente pelos elevados custos de energia e insumos despendidos [3,4].

Em virtude disso, paulatinamente, surgiu a necessidade de se buscar alternativas dentro de um cenário da hidrometalurgia extrativa: a) expectativa com a diminuição dos recursos minerais; b) necessidades comerciais se ampliando devido ao desenvolvimento tecnológico; c) aumento da produção de bens de consumo. Estes aspectos completam a matemática que impulsiona essa busca pelo aproveitamento máximo das reservas minerais no qual os processos bio-hidrometalúrgicos para obtenção de metais não-ferrosos se enquadram.

Durante as últimas décadas, os processos industriais que empregam micro-organismos na extração e recuperação de metais não-ferrosos vêm se tornando economicamente atrativos e viáveis devido a três fatores: melhorias dos processos; necessidades econômicas e busca de uma mineração sustentável [4-7].

'Coordenação de Processos Metalúrgicos e Ambientais, Serviços de Processos Minerometalúrgicos e Biotecnológicos, Centro de Tecnologia Mineral CETEM, Rio de Janeiro, RJ, Brasil. E-mail: egiese@cetem.gov.br

2176-1523 (C) ano Associação Brasileira de Metalurgia, Materiais e Mineração. Publicado pela ABM. Este é um artigo de acesso aberto distribuído sob os termos da licença Creative Commons CC BY-NC-ND (Attribution-NonCommercial-NoDerivs) - https:// creativecommons.org/licenses/by-nc-nd/4.0\%. 
A lixiviação bacteriana, ou biolixiviação, é um ramo da bio-hidrometalurgia que utiliza micro-organismos para a obtenção de metais a partir de minérios de baixo teor e rejeitos da mineração, podendo ainda ser aplicada no pré-tratamento de sulfetos minerais para extração de ouro e prata [6].

Este processo bio-hidrometalúrgico baseia-se na capacidade de micro-organismos acidófilos e quimiolitotróficos, tais como os pertencentes aos gêneros Acidithiobacillus, Leptospirillum, Sulfobacillus, Sulfolobus e Acidianus, em oxidar o ferro(II) e/ou espécies reduzidas de enxofre com a consequente extração do metal de interesse [7].

Apesar das limitações do processo no curto e médio prazos, verifica-se um crescente interesse dos agentes econômicos na biomineração, a qual vem apresentando elevado potencial tecnológico para a obtenção de metais a partir de reservas ainda não exploradas por apresentarem baixo teor do metal de interesse. Quadro este no qual a biolixiviação pode ser considerada uma alternativa de mineração sustentável frente ao crescimento global e da conseqüente demanda por tecnologias e bens de consumo.

\section{I.I Breve Histórico da Biolixiviação}

A bioextração de metais não-ferrosos com o uso de micro-organismos, em verdade, é uma técnica de conhecimento milenar, sendo a exploração comercial das minas de Rio Tinto em 1890, no sudoeste espanhol, considerada o berço da bio-hidrometalurgia moderna [8]. Nestas primeiras operações comerciais, as pilhas de minério de cobre de baixo teor $(0,75 \% \mathrm{~m} / \mathrm{v})$ atingiam 10 metros de altura e o processo ocorria naturalmente a céu aberto, com o rendimento de extração anual de 20 a $25 \%$ do cobre residual [9].

Já os primeiros estudos científicos sobre biolixiviação foram publicados em fins da década de 40 do século passado. Em 1947, o envolvimento de bactérias na oxidação da pirita nas drenagens ácidas de minas foi descrito por Colmer e Hinkle [10]. Dez anos depois, a empresa americana Kennecott Copper Corp. realizou a primeira requisição de proteção de tecnologia: um processo de biolixiviação em pilha de minérios sulfetados de baixo teor de cobre baseada na atividade da bactéria Thiobacillus ferrooxidans e na irrigação das pilhas com água acidificada contendo íons ferro(III) [I I].

\section{I.2 Mecanismos da Biolixiviação}

Até a década de 80, acreditava-se que o processo de lixiviação microbiana ocorria por meio de dois mecanismos: i) mecanismo direto, onde os micro-organismos realizariam a dissolução do mineral através da ação de enzimas específicas secretadas pelos mesmos; ii) mecanismo indireto, onde o mineral seria atacado quimicamente por íons ferro(III); sendo os micro-organismos presentes na lixívia responsáveis pela regeneração do agente oxidante. $O$ enxofre elementar $\left(S_{0}\right)$ formado durante a reação também seria oxidado pela ação de micro-organismos com a formação de ácido sulfúrico [12-15].

A interação micro-organismo/sulfeto mineral é fundamental no processo, uma vez que o biofilme bacteriano formado em consequência da adesão celular é capaz de complexar os íons ferro(III) e potencializar as reações oxidativas na superfície do sulfeto mineral [16].

A estrutura mineral é o fator determinante para o tipo de reação de solubilização do metal de interesse. Alguns sulfetos ( $\mathrm{PbS}, \mathrm{CuFeS}_{2}, \mathrm{ZnS}, \mathrm{MnS}_{2}, \mathrm{As}_{2} \mathrm{~S}_{3}, \mathrm{As}_{3} \mathrm{~S}_{4}$ ) produzem enxofre elementar como produto de oxidação e outros $\left(\mathrm{FeS}_{2}, \mathrm{MoS}_{2}, \mathrm{WS}_{2}\right)$ produzem sulfatos. De acordo com os produtos reacionais, os mecanismos de oxidação dos sulfetos minerais são denominados de a) mecanismo do tiossulfato (Equações I e 2), baseado no ataque oxidativo por íons ferro(III), e b) mecanismo do polissulfeto (Equações 3, 4 e 5), baseado no ataque oxidativo por íons ferro(III) e prótons [7].

$$
\begin{aligned}
& \mathrm{FeS}_{2}+6 \mathrm{Fe}^{3+}+3 \mathrm{H}_{2} \mathrm{O} \rightarrow \mathrm{S}_{2} \mathrm{O}_{3}^{2-}-7 \mathrm{Fe}^{2+}+6 \mathrm{H}^{+} \\
& \mathrm{S}_{2} \mathrm{O}_{3}^{2-}+8 \mathrm{Fe}^{3+}+5 \mathrm{H}_{2} \mathrm{O} \rightarrow 2 \mathrm{SO}_{4}^{2-}+7 \mathrm{Fe}^{2+}+10 \mathrm{H}^{+} \\
& 2 \mathrm{MS}+2 \mathrm{Fe}^{3+}+2 \mathrm{H}^{+} \rightarrow 2 \mathrm{M}^{2+}+\mathrm{H}_{2} \mathrm{~S}_{n}+2 \mathrm{Fe}^{2+} \\
& \mathrm{H}_{2} \mathrm{~S}_{n}+2 \mathrm{Fe}^{3+} \rightarrow 1 / 4 \mathrm{~S}_{8}+2 \mathrm{Fe}^{2+}+2 \mathrm{H}^{+} \\
& 1 / 4 \mathrm{~S}_{8}+\mathrm{O}_{2}+2 \mathrm{H}_{2} \mathrm{O} \rightarrow 2 \mathrm{SO}_{4}^{2-}+4 \mathrm{H}^{+}
\end{aligned}
$$

A relação entre as concentrações molares de íons ferro(II) e íons ferro(III) definem o potencial eletroquímico do sistema (Eh), sendo este um dos principais parâmetros de controle do processo de biolixiviação e indicativo de sua eficiência.

Além das características químicas do mineral, os processos bio-hidrometalúrgicos para a solubilização de metais são também influenciados por diversos parâmetros ambientais que podem intervir na eficiência e rendimento das operações (Figura I).

No início das operações industriais de biolixiviação, no final do século XIX, muitos destes aspectos eram negligenciados e/ou desconhecidos, o processo era realizado de modo rudimentar. A partir da metade do século XX alguns aspectos minerais, físico-químicos e biológicos começaram a ser controlados com o intuito de se aumentar o rendimento do processo resultando em inovações tecnológicas de aplicabilidade industrial.

\section{I.3 Técnicas para Aplicação da Biolixiviação}

As técnicas mais utilizadas, tanto em escala piloto como comercial, para aplicação deste processo bio-hidrometalúrgico são constituídas pela: I) biolixiviação 
em pilhas ("heap leaching”), 2) biolixiviação em montes (“dump leaching”) e 3) biolixiviação em tanques agitados.

O processo industrial de biolixiviação em pilha ("heap leaching") aproveita da ação natural das bactérias presentes na pilha de minério e da adição de consórcios microbianos que atuam na aceleração do processo de solubilização dos metais. Os minerais em questão devem ser constituídos de formas reduzidas de enxofre e ferro, os quais serão depositados na forma de pilha sobre uma base impermeabilizada (Figura 2). A supérfície da pilha é então irrigada com uma solução ácida, prontamente recuperada após a percolação e reutilizada no processo. A irrigação facilita o aumento da atividade microbiana, resultando no aumento da acidez, no favorecimento das reações de oxidorredução decorrentes da produção de ácido sulfúrico "in situ” e na geração de íons ferro(III). Desta maneira, ao final do processo, o metal de interesse é solubilizado e recuperado [17,18].

A biolixiviação em montes (“dump leaching”) é baseada no mesmo mecanismo, porém utilizada em depósitos já existentes de rejeitos minerais próximos às minas, nos quais o teor do metal é baixo demais para o custo de sua recuperação [19].

Já no caso dos tanques agitados, a interação da superfície mineral e os agentes oxidantes é superior e garante maior eficiência: a polpa formada pelo agente lixiviante e a amostra mineral moída é agitada continuamente para evitar

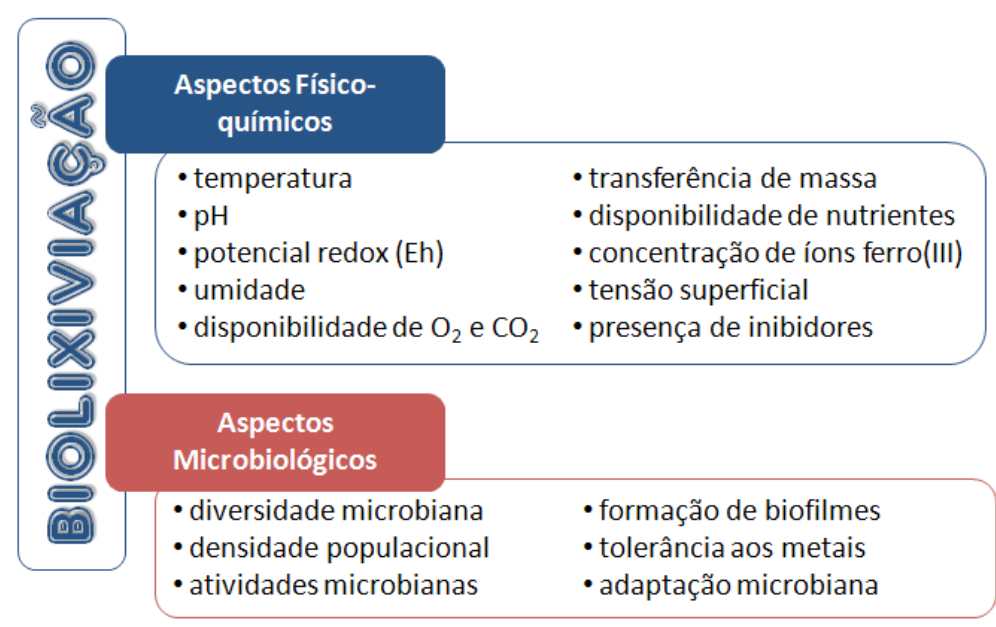

\section{Aspectos Minerais}

- tipo e composição do mineral

- tamanho das partículas

-área superficial

- porosidade e hidrofobicidade do material

Figura I. Aspectos físico-químicos, microbiológicos e minerais envolvidos na biolixiviação.

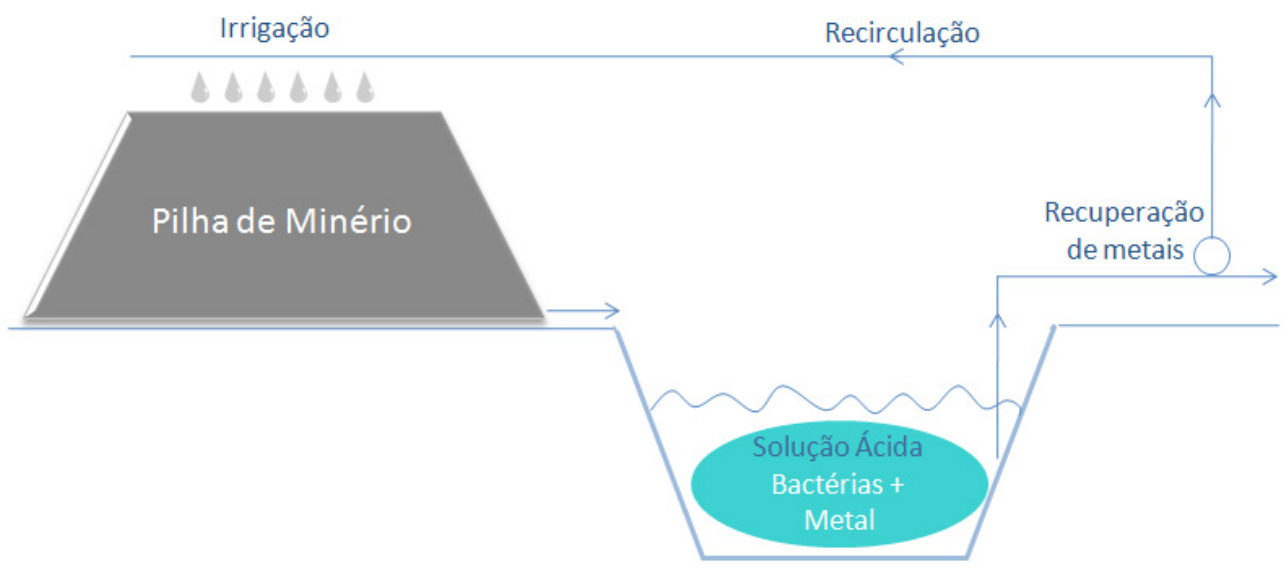

Figura 2. Esquema do processo de biolixiviação em pilha (“heap leaching”). 
a sedimentação de sólidos. Tal processo de biolixiviação é comumente aplicado para o tratamento de concentrados da flotação de minérios sulfídicos contendo ouro e urânio e, eventualmente, metais de base como cobre, níquel, zinco e cobalto [8].

A empresa de pesquisa mineral Mintek, da África do Sul, desenvolveu o processo $B$ cox $^{\mathrm{TM}}$ para biolixiviação de ouro, e fornece a tecnologia para plantas comerciais mundo à fora. Um exemplo é a planta desenvolvida em 1999 na Tasmânia (Austrália), com capacidade de tratar 70 toneladas/dia de concentrado refratário de pirita-arsenopirita com rendimento de extração de ouro de $95 \%$ [20]. As inovações da área incluem, v.g., o uso de tanques agitados à altas temperaturas [2I] e a extração de metais de interesse com reatores conectados em série [22].

O conhecimento dos limites da tecnologia já existente é necessário para que as pesquisas em biolixiviação, de um lado, se antecipem às necessidades reais do setor mineral $\mathrm{e}$ seus resultados sejam posteriormente aplicados nas operações industriais mineiras, e de outro lado permite projetar novos caminhos a trilhar. Neste contexto, a prospecção de novas tecnologias através da análise de pedidos de patente é uma ferramenta que auxilia na definição de estudos a serem conduzidos visando melhorias significativas em produtos e processos [23].

Neste contexto, o objetivo deste estudo foi mapear o conhecimento tecnológico do uso de micro-organismos em processos de biolixiviação na indústria de hidrometalurgia extrativa com o intuito de caracterizar o perfil das inovações tecnológicas depositadas nos últimos 25 anos.

\section{METODOLOGIA}

O mapeamento dos pedidos de patentes e tecnologias depositadas entre os anos de 1991 e 2016 consistiu na busca pela palavra-chave "bioleaching" na base de dados Patentscope (WIPO) que tem atualização periódica, cuja base importa atualmente patentes de 148 países, incluindo ainda o Tratado de Cooperação de Patentes (PCT), com atualização periódica.
As patentes foram tratadas seguindo-se de inserção de seus dados em gráficos plotados em Excel 20 I0. As pesquisas na base de dados foram atualizadas pela última vez na data de 06/06/2016.

\section{RESULTADOS E DISCUSSÃO}

\section{I Área de Abrangência e Distribuição Cronológica das Patentes: A Era das Commodities}

A Classificação Internacional de Patentes (CIP) surgiu com o intuito de estabelecer uma ferramenta de busca eficaz para a recuperação de documentos de patentes pelos escritórios de propriedade intelectual e demais usuários. Os principais códigos CIP do conteúdo técnico das patentes em biolixiviação são C22B 3/04 e C22B 3/ I8, referentes à extração de compostos metálicos de minérios ou concentrados por processos a úmido por lixiviação com o auxílio de micro-organismos.

A classe CIP C22 compreende invenções e tecnologias correlatas na área de química e metalurgia, onde o grupo C22B 3/00 classifica os processos de extração de compostos metálicos de minérios ou seus concentrados por processos a úmido (hidrometalurgia). A Tabela I apresenta as áreas de abrangência dos sub-grupos que classificam o processo de extração de compostos metálicos por lixiviação na presença de micro-organismos.

A busca realizada com a palavra-chave "bioleaching" rastreou 328 documentos patenteados, enquanto que a busca com os códigos C22B 3/04 e C22B 3/ 18 rastreou apenas $21 \mathrm{I}$ patentes. Esta lacuna entre o número de documentos adquiridos pode ser atribuída à classificação inadequada do objeto de patente ou à estratégia do inventor em dificultar a disponibilização de informações sobre sua invenção buscando limitar seu uso e divulgação.

Assim, para o desenvolvimento do presente trabalho, optou-se pela análise dos documentos de patente depositados contendo a palavra-chave "bioleaching". A Figura 3 demonstra a evolução anual dos depósitos das patentes sobre a temática

Tabela I. Área de abrangência dos sub-grupos da classificação internacional de patentes C22B (produção ou refino de metais; pré-tratamento de matérias primas) relacionadas ao processo de biolixiviação

\begin{tabular}{lcll}
\hline \multicolumn{3}{c}{ Código CIP } \\
\hline Seção C & Química, Metalurgia & \\
\hline Classe C22 & Metalurgia; ligas ferrosas ou não-ferrosas; \\
& tratamento de ligas ou de metais não-ferrosos \\
\hline & Subclasse & Produção ou refino de metais; \\
& C22B & pré-tratamento de matérias primas \\
\hline & Grupo & Extração de compostos metálicos de minérios ou concentrados por processos \\
& C22B 3/00 & a úmido & \\
\hline & Subgrupos & C22B 3/04 & por lixiviação \\
\hline & C22B 3/18 & com auxilio de micro-organismos ou enzimas
\end{tabular}


de extração de compostos metálicos por lixiviação na presença de micro-organismos no período de $199 \mathrm{I}$ à 2015.

Uma análise preliminar sugere um aumento significativo no depósito de patentes a partir do início do século XXI, tendo sido mapeados 35 pedidos de privilégio entre |99|-2000 e $2 \mathrm{II}$ pedidos entre $200 \mathrm{I}-20 \mathrm{I} 0$.

O crescimento acelerado da economia chinesa a partir dos anos 2000, espantosos $10,7 \%$ a. a., provocou um "boom", ocasionando uma alta na demanda global por bens minerais que impulsionou os preços internacionais de commodities, que aceleraram $227 \%$ no período entre 2000 e 2008 [24].

No que tange ao setor mineral de não-ferrosos (prata, cobre, chumbo, alumínio e níquel), os indicadores de desempenho de exportação dos BRIC (Brasil, Rússia, Índia, China) revelaram que a evolução positiva da China apresentou relação direta com a taxa de crescimento nas exportações destes minerais ao longo do período [25], o que pode ter favorecido a busca por novas tecnologias de hidrometalurgia extrativa para promover a oferta destes recursos minerais.

Os preços das commodities minerais foi impulsionado pelo aumento dos investimentos em infraestrutura atingindo o ápice em 2007 (Figura 4). No Brasil, o aumento na demanda por minerais impulsionou o valor da Produção Mineral
Brasileira (PMB), o qual alcançou o patamar máximo de sua história em 201 I com negócios de US\$ 53 bilhões, o que representou um aumento de $28 \%$ em relação a 2010 . A partir de 2012 registrou-se queda gradativa da PMB, chegando a apenas US\$26 bilhões em 2015, o que representou uma queda de $35 \%$ em relação ao ano interior e à metade do valor negociado em 20 II [26].

O aumento do preço das commodities esteve associado à períodos de prosperidade econômica, rápida urbanização e aumento da demanda pelo crescimento na produção industrial. Quadro que estimulou os investimentos em inovação e produção, o que pode, no caso dos metais não-ferrosos, ter contribuído para o aumento significativo do número de depósito de patentes no período.

Já diante da crise econômica global ocorrida no pós 2008, o preço dos metais não-ferrosos recuou, e partir de 2012 a demanda chinesa por commodities metálicas diminuiu frente à desaceleração econômica e rebalanceamento dos investimentos com consequente queda dos preços internacionais até os dias atuais.

Com o fim do super ciclo das commodities, os agentes econômicos, públicos e privados, têm um grande desafio pela frente: prover e utilizar novas tecnologias para exploração de minerais de baixo teor de metais a fim

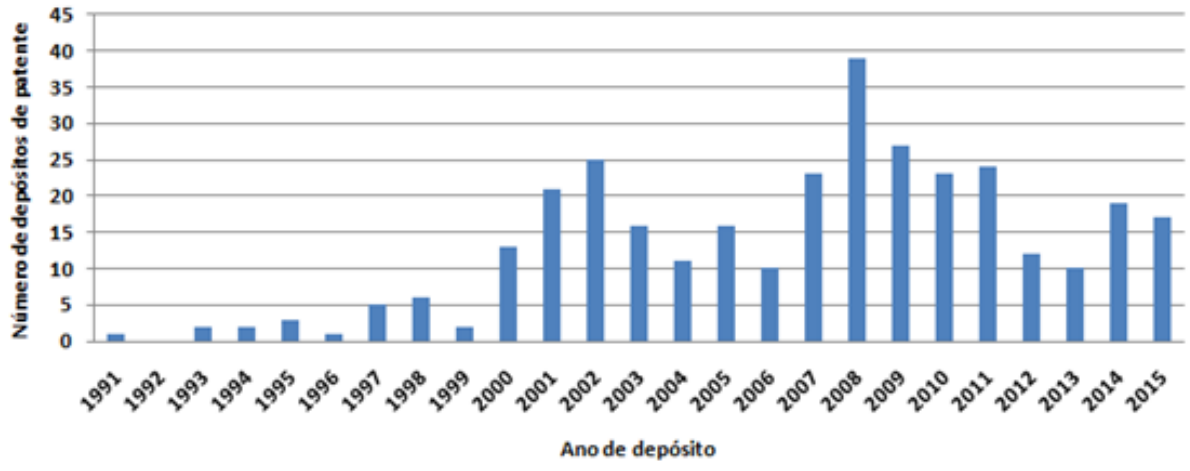

Figura 3. Distribuição cronológica dos depósitos de patentes sobre a temática biolixiviação no período de |99|-2015.

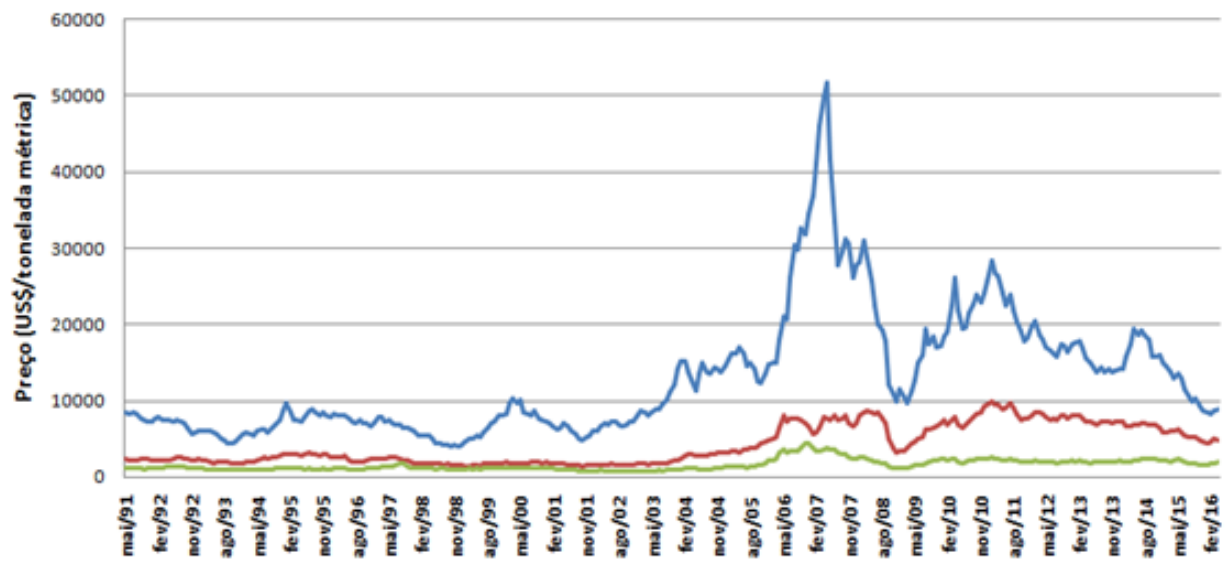

Figura 4. Preço mensal dos metais não-ferrosos níquel (-), cobre (-) e zinco (-) no período de I99|-20I5. Fonte: World Bank [27]. 
de fornecer a matéria-prima de maneira mais eficiente e sustentável mesmo num ambiente econômico adverso.

\subsection{Distribuição Geográfica: Pedidos de Proteção à Inovação e Investimento Privado em Pesquisa Mineral}

Os depósitos de patentes, no período avaliado, foram realizados em 13 países, incluindo-se ainda o Tratado de Cooperação em matéria de Patentes (PCT), o Escritório Europeu de Patentes (EPO), o Escritório de Patentes da Eurásia (EAPO) e Organização Regional Africana de Propriedade Industrial (ARIPO) como apresentado na Figura 5.

A China e os EUA dispõem da maior quantidade das tecnologias para biolixiviação depositadas em seus territórios, totalizando 74 e 72 documentos de patentes registrados, respectivamente, seguido pelo PCT (50 depósitos) e Canadá (4I depósitos).

Sabe-se que nos últimos 20 anos, a exploração das reservas chinesas em diferentes commodities minerais cresceu substantivamente, em virtude da "descoberta" de novas fronteiras minerais. Em 20I4, por exemplo, foram mapeadas novas reservas de zinco, chumbo, cobre e prata na província de Hunan [28].

Apesar disso, o avanço chinês foi responsável por aproximadamente $6 \%$ do orçamento de exploração global em 20 I4, enquanto que Canadá e Austrália foram os países que mais se destacaram pelo investimento da iniciativa privada em projetos de pesquisa mineral de não-ferrosos (Figura 6). Em 20l4, este investimento foi estimado em US\$ II,4 bilhões, enquanto que em 2013 foi da ordem de US\$15,2 bilhões, o que corresponde à uma queda de $26 \%$ [29].

Para efeitos comparativos, apesar das reservas minerais, de acordo com a SNL Metals \& Mining, o Brasil figura como um dos países com menor investimento, totalizando apenas $3 \%$ do montante geral, atrás inclusive, de outros países da América Latina, tais como: México, Chile, Peru, Colômbia e Argentina [30].

Dentro do orçamento para exploração de metais de base houve uma queda de $21 \%$ em relação ao ano de 2014 (US $\$ 3,7$ bilhões) para o ano de 2013 (US $\$ 4,7$ bilhões). Os 10 países com maior investimento para exploração de zinco/chumbo foram: China, Canadá, México, Austrália, Peru, Congo, Suécia, Índia, Irlanda e Estados Unidos. Os 10 países com o maior orçamento de exploração de níquel foram: Austrália, Canadá, Rússia, Indonésia, China, Estados Unidos, Finlândia, Brasil, Tanzânia e Filipinas [30].

A exploração de cobre representou mais de $70 \%$ do orçamento de metais de base para 2014 , sendo que os 10 países com maior investimento para este fim, em ordem decrescente, foram: Chile, Austrália, Peru, Congo, Estados Unidos, Canadá, China, Zâmbia, México e Brasil.

Atualmente $\circ$ Chile recebe destaque mundial como um importante desenvolvedor de tecnologias em biolixiviação. Em 200I, v.g., os processos de biolixiviação já constituíam cerca de $10 \%$ da extração de cobre do país, com 13 empresas empregando industrialmente esta biotecnologia.

A Codelco, empresa de cobre estatal chilena, é responsável por II\% da produção mundial de cobre. Em 2002, associou-se com a japonesa JX Nippon Mining and Metals Corp., criando a BioSigma, cujo propósito é incorporar avanços na mineração, desenvolvendo e comercializando tecnologias para a biolixiviação. A BioSigma recebeu o prêmio Avonni 2015 em mineração e metalurgia pelas inovações tecnológicas na extração biológica de cobre de materiais refratários à temperatura ambiente [3I].

De acordo com o levantamento realizado no rastreio de depósito de invenções, a BioSigma (Chile), Boliden Mineral (Suécia), Geobiotics LLC (Estados Unidos) e BHP Billiton LTD (Inglaterra) foram as principais empresas cessionárias das tecnologias patenteadas.

\section{3 Áreas de Abrangência e Principais Inovações em Biolixiviação}

A Figura 7 ilustra as diferentes áreas de abrangência encontradas na distribuição dos documentos de patentes em biolixiviação e tecnologias correlatas, depositadas na OMPI por códigos de classificação internacional (CIP).

A classe $C 22 B$ (produção ou refino de metais; pré-tratamento de matérias primas) foi a que demonstrou maior frequência entre os depósitos de patentes rastreados, seguida pelas classes $\mathrm{CI} 2 \mathrm{~N}$ (micro-organismos), $\mathrm{C} 02 \mathrm{~F}$ (tratamento de água), $\mathrm{Cl} 2 \mathrm{P}$ (processos que utilizem enzimas para sintetizar uma composição ou composto químico), $\mathrm{Cl} 2 \mathrm{R}$ (relativo à classificação dos micro-organismos), $\mathrm{CI} 2 \mathrm{~S}$ (processos que utilizam micro-organismos para separação) e CI2M (aparelhos para microbiologia).

A maioria dos documentos de patentes selecionados está relacionada com a Seção C (Química e Metalurgia) da CIP, enquadrando-se ainda as seções B (Operações de Processamento), G (Física) e $\mathrm{F}$ (Aquecimento).

$\mathrm{Na}$ área de metalurgia de metais não-ferrosos (C22), os depósitos de patentes são baseados principalmente na extração de compostos metálicos de minérios por via úmida ( $C 22 B$ 3/00), especialmente por lixiviação (C22B 3/04) na presença de soluções inorgânicas ácidas como o ácido sulfúrico (C22B 3/08) com o uso de micro-organismos ( $C 22 \mathrm{~B} 3 / \mathrm{l}$ ). A maioria das patentes está concentrada na área de obtenção do cobre $(C 22 B \quad 15 / 00)$, seguida pela obtenção do níquel ou do cobalto (C22B 23/00) e de metais nobres (C22B I I/00).

Algumas das principais inovações patenteadas encontram-se descritas a seguir.

\subsection{Temperatura}

O aquecimento das pilhas de biolixiviação é uma preocupação constante, principalmente em plantas localizadas em regiões com baixas temperaturas como as encontradas na mina chilena Quebra Blanca ou na finlandesa Talvivaara. 


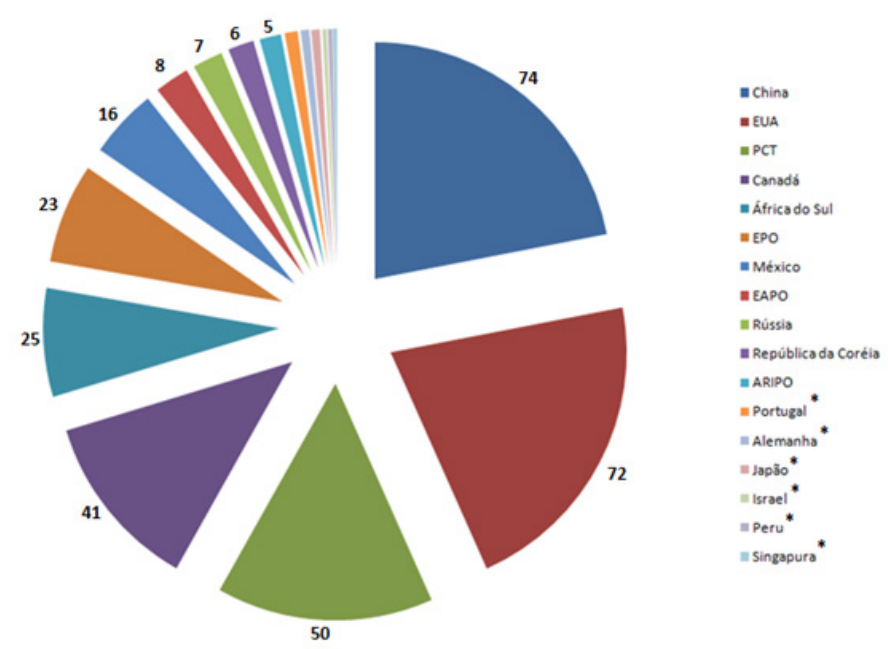

Figura 5. Distribuição geográfica do número de depósitos de patentes prospectados em países de prioridade sobre a temática biolixiviação no período de 199I-20I5. PCT: Tratado de Cooperação em matéria de Patentes; EPO: Escritório Europeu de Patentes; EAPO: Escritório de Patentes da Eurásia; ARIPO: Organização Regional Africana de Propriedade Industrial. * número de depósitos de patentes $\leq 3$.

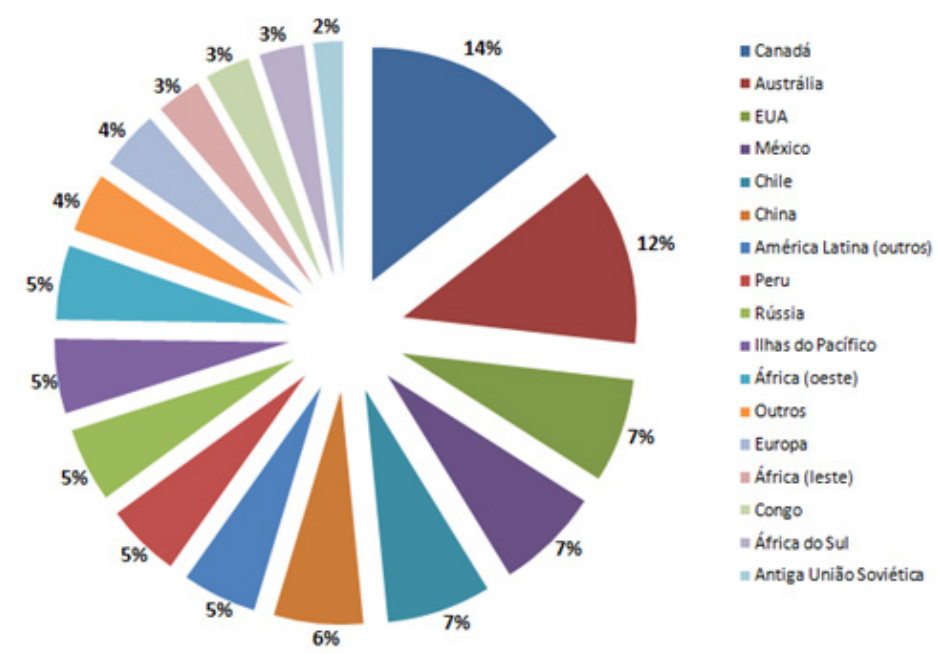

Figura 6. Distribuição geográfica do investimento privado em pesquisa mineral de não-ferrosos em 20I4. Fonte: SNL Metals \& Mining. World Exploration Trends 2015 [29].

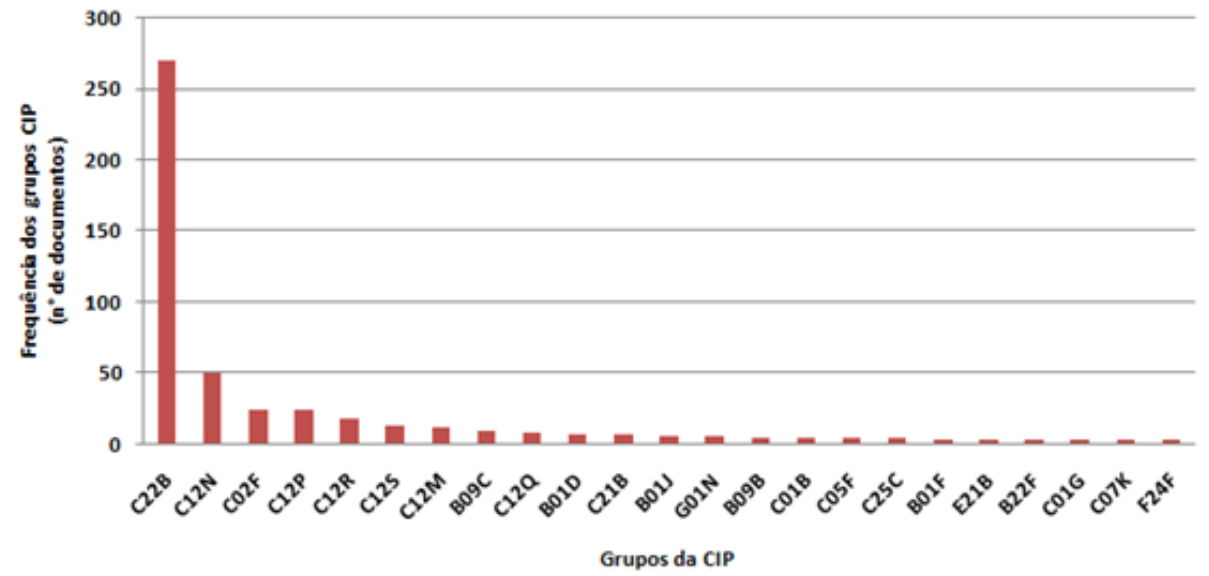

Figura 7. Freqüência dos grupos da Classificação Internacional de Patentes utilizados nos depósitos de patentes relacionados à biolixiviação e tecnologias correlatas depositados no Brasil no período de |99|-20I5. 
A dissolução dos sulfetos minerais por micro-organismos acidófilos termófilos resistentes à altas temperaturas apresenta rendimentos de até $90 \%$ em relação aos mesófilos e são fundamentais na continuidade da oxidação do minério quando a temperatura no interior da pilha atinge valores entre 65 e $95^{\circ} \mathrm{C}$, decorrente do calor gerado pelas reações de oxidação que promovem a solubilização do metal de interesse [32].

O depósito da empresa Technological Resources Pty. Limited aborda uma tecnologia de aquecimento eletromagnético para geração de calor "in situ" das pilhas. Neste caso, o sistema de biolixiviação estaria exposto à radiações magnéticas de baixa radiofrequência $(5-45 \mathrm{MHz})$ promovendo a manutenção da temperatura entre 45 e $65^{\circ} \mathrm{C}$, e até $85^{\circ} \mathrm{C}$ no caso do minério em questão se tratar de sulfetos de cobre ou calcopirita. $O$ aquecimento eletromagnético se dá, neste caso, pela disposição de diversos eletrodos verticalmente protegidos por uma malha metálica de modo a impedir que os mesmos sejam transmitidos para fora da pilha [33].

\subsubsection{Eh}

A outra patente da empresa Technological Resources Pty. Limited permite o controle das taxas de irrigação e aeração a partir da verificação da oxidação do material no interior da pilha [34]. O potencial de oxirredução (Eh) nos processos de biolixiviação é determinado pela relação entre as concentrações das espécies iônicas de ferro $\left(\mathrm{Fe}^{2+}\right.$ e $\left.\mathrm{Fe}^{3+}\right)$. A dissolução dos sulfetos minerais, e a consequente solubilização dos metais, acontece quando ocorre a oxidação dos íons $\mathrm{Fe}^{3+}$. Desta maneira, a medida o Eh pode ser utilizada no monitoramento do processo para que o sistema operacional seja favorável à manutenção do sistema reacional [35].

\subsubsection{Agentes lixiviantes}

Um exemplo do incremento na utilização de agentes lixiviantes é o uso do pré-tratamento do minério com uma solução de ácido sulfúrico (acima de $2 \mathrm{~g} / \mathrm{L}$ ) contendo íons $\mathrm{Fe}^{3+}(10-12 \mathrm{~g} / \mathrm{L})$ à $100^{\circ} \mathrm{C}$ para posterior etapa de biolixiviação [36]. A presença de íons $\mathrm{Fe}^{3+}$ é fundamental na lixiviação de minérios sulfetados por controlar o potencial de óxido-redução, o qual está diretamente relacionado à velocidade da reação e rendimento da operação [37].

O uso extensivo de ácido sulfúrico na biolixiviação, especialmente na pilha e no manejo do despejo da lixívia, tem despertado o interesse na produção de ácido sulfúrico "in situ" pela própria atividade microbiana do bioprocesso.

O Centro de Tecnologia Mineral (CETEM/MCTIC) realizou recentemente depósito de patente da invenção de um processo para a biolixiviação de minérios primários de cobre, níquel, zinco, cobalto, molibdênio, urânio, metais preciosos e rejeitos com produção biológica simultânea de ácido sulfúrico a partir de enxofre elementar e/ou pirita [38].
Neste processo, a bactéria Acidithiobacillus thiooxidans, pertencente ao "blend" de micro-organismos lixiviantes, oxida o enxofre elementar $\left(S_{0}\right)$ concomitantemente com a produção de ácido sulfúrico. A lixiviação do minério com produção "in situ" de ácido sulfúrico garante a homogeneidade do processo uma vez que a solução irrigada no topo tende a percolar a pilha e, principalmente, permite a manutenção da temperatura da pilha pelo calor gerado do processo de biooxidação do $S_{0}$ [39].

\subsection{4 Ácidos orgânicos}

A BHP Minerals INT INC, empresa americana na área de mineração, depositou duas patentes no Brasil referentes ao uso de ácidos orgânicos simultaneamente ao ácido sulfúrico nas pilhas de biolixiviação. Uma das patentes refere-se a um processo de lixiviação de um minério contendo níquel e magnésio, com o uso de um micro-organismo capaz de produzir um ácido orgânico que auxilia na dissolução do minério para posterior separação do níquel e magnésio em solução [40]. O uso de consórcios microbianos de bactérias autotróficas e bactérias ou fungos heterotróficos tem sido descrito na literatura. A produção de ácido lático, oxálico, cítrico e glucônico, por exemplo, auxiliam na solubilização direta do metal para a líxivia tanto pela troca direta de cátions quanto pela formação de complexos metálicos solúveis e quelatos [4I].

\subsubsection{Densidade celular}

Uma vez que a biolixiviação é um processo baseado na interação micro-organismo substrato mineral, a concentração celular é outro fator fundamental para o rendimento do processo. Neste sentido, algumas patentes visam a aglomeração de substâncias junto ao minério que favoreçam a bio-aumentação e a bioestimulação da microbiota presente no sistema, como a pleiteada pela empresa americana Freeport-McMoran Corporation [42].

Já a bioaumentação é uma prática muito comum nos processos de biolixiviação em pilha, pois consiste em se adicionar cepas de micro-organismos ("blends") específicos num esforço de se aumentar a atividade microbiana das comunidades nativas presentes no minério. Esta técnica é comumente denominada como inoculação das pilhas e é realizada através da irrigação de uma solução acídica contendo nutrientes e células microbianas.

Ultimamente, o uso de "blends" imobilizados tem sido avaliado como uma maneira de bioaumentar a população microbiana e garantir uma melhor eficiência do processo com menor geração de lixívias ácidas $[43,44]$. Neste sentido, a BioSigma patenteou recentemente uma técnica de bioaumento e bioestimulação baseada em cápsulas de alginato contendo cepas microbianas e íons $\mathrm{Fe}^{3+}$ chamadas de "Biosigma bioleaching seeds" [45].

O crescimento microbiano de determinada espécie microbiana também pode ser promovido por moléculas sinalizadoras de quorum sensing (QS). O QS pode ser 
descrito como um mecanismo de comunicação entre as bactérias que ocorre através da produção de pequenas moléculas sinalizadoras que são detectadas por receptores específicos e permitem que as células monitorem sua densidade populacional [46]. No caso específico da biolixiviação, o uso de moléculas sinalizadoras de QS é válido pois este tipo de interação reflete diretamente na formação de biofilme, o que é primordial para a interação micro-organismo-substrato mineral.

A empresa dinamarquesa Flsmifth A. S. inovou este processo biohidrometalúrgico ao propor o uso de lixívia contendo metaloenzimas de origem microbiana que contenham íons cobre e estruturas Fe-S em seu sítio ativo (cuprodoxina, citocromos, proteínas Fe-S), assim como moléculas sinalizadoras de quorum sensing como $\mathrm{N}$-acil-homoserina lactonas (AHLs) [47].

\subsubsection{Biofilme}

Uma das inovações consiste em um método de introdução de micro-organismos (inóculo) na pilha a partir do preparo de células microbianas cuja a produção de exopolímeros nas paredes externas seja ativada após inoculação das mesmas, através da inibição de enzimas do ciclo do ácido cítrico [48]. A presença dessas substâncias é fundamental tanto para a adesão microbiana quanto para melhor desempenho do processo de biolixiviação, uma vez que a interação entre as bactérias lixiviantes e a superfície dos sulfetos minerais ocorre através da formação de um biofilme. Uma vez formado, os sítios ativos presentes serão capazes de formar complexos com os íons $\mathrm{Fe}^{3+} \mathrm{e}$ potencializar as reações oxidativas na superfície do sulfeto mineral, acelerando sua dissolução [16].

\section{CONSIDERAÇÕES FINAIS}

O setor mineral, base para diversas cadeias produtivas, apresenta considerável peso econômico para muitos países, não à toa algumas mineradoras terem suas ações consideradas blue chips nos mercados. No ano de 2014, por exemplo, cerca de $5 \%$ do PIB industrial do Brasil era caudatório desse ramo econômico. O país se destaca no cenário global tanto em reservas, quanto pela produção de minério de ferro, bauxita e manganês, entre vários outros bens minerais.

A indústria brasileira de não-ferrosos começou a ser impulsionada na década de 1950, seguindo o modelo de industrialização adotado pelos países em desenvolvimento no período pós-guerra, que visava o crescimento econômico e social a partir da substituição das importações e expansão comercial. Estes países, incluindo o Brasil, almejaram deixar de ser fornecedores exclusivos de matérias-primas para passar a exportar bens industriais com participação de empresas multinacionais próprias buscando fugir do jugo das potências centrais.

O código da mineração, de 1967, provocou o crescimento do setor pro regulamentar o setor, criando regras mais modernas, de um lado, e por admitir a abertura de capital estrangeiro impulsionando a exploração de metais primários como o alumínio, o chumbo, o cobre, o níquel, o estanho e o zinco, minorando a escassez de capital do setor. Atualmente, há cenário de expectativa por parte dos agentes econômicos do ramo mineral em virtude de dois fatores: a discussão de um novo marco regulatório e, em paralelo, a desaceleração econômica mundial, que reverteu os preços atrativos das commodities.

A despeito disso, a indústria hidrometalúrgica brasileira necessita inovar para adequar a tecnologia às necessidades e estratégias de mercado. A prospecção das inovações tecnológicas contidas nos depósitos revelou oportunidades para este segmento e necessidades tecnológicas relevantes na área de bio-hidrometalurgia, sobretudo no que diz respeito à biolixiviação.

O avanço do desenvolvimento de C\&T nesse segmento é de grande importância para o Brasil uma vez que a exploração de minérios de baixo teor apresenta atrativos econômicos crescentes e os concentrados refratários não são facilmente tratados pelos métodos metalúrgicos convencionais.

É necessário o estabelecimento de políticas governamentais e de estratégias de pesquisa e desenvolvimento de longo curso visando estimular parcerias entre centros de pesquisas, universidades e empresas; buscando estimular assim, o aumento dos índices nacionais de inovação em métodos bio-hidrometalúrgicos para extração de metais a partir de minérios de baixo teor e rejeitos da mineração.

A análise dos depósitos de inovação dos últimos anos demonstram que o domínio do conhecimento das técnicas de biolixiviação ainda se apresenta fragmentado. Muitas lacunas estão sendo estudadas e novas tecnologias vêm surgindo com o objetivo de minimizar o tempo operacional e facilitar a implementação industrial da bio-hidrometalurgia visando sua viabilidade econômica.

O monitoramento das patentes depositadas no mundo pode ser uma ferramenta quando da elaboração de estratégias de inovação e exploração de segmentos específicos. As patentes rastreadas sugerem a modernização de aparatos utilizados nos processos de biolixiviação assim como pretendem resolver possíveis problemas operacionais ocasionados por parâmetros físico-químicos e biológicos que afetam diretamente o rendimento da biolixiviação.

\section{REFERÊNCIAS}

I Luz AB, Sampaio JA, França SCA. Tratamento de minérios. 5. ed. Rio de Janeiro: CETEM/MCTI; 2010.

2 Haglund D, Roe A, Ericsson M, Hodge A. The role of mining in national economics. 2. ed. Oxford Police Management; 2014 [acesso em 22 jan. 20I6]. 284 p. Disponível em: www.icmm.com/document/8264 
3 Guézennec A-G, Hanke M, Chmielarz A, Joulian C, Menard Y, D'Hugues P. Bio-hydrometallurgy: an alternative to pyrometallurgy for copper recovery in a polymineral concentrate. Hydrometallurgy. 20I4. 10 p.

4 Panda S, Akcil A, Pradhan N, Deveci H. Current scenario of chalcopyrite bioleaching: a review on the recent advances to its heap-leach technology. Bioresource Technology. 2015;196:694-706. PMid:263 I8845. http://dx.doi. org/10.1016/j.biortech.2015.08.064.

5 Kutschke S, Guézennec AG, Hedrich S, Schippers A, Borg G, Kamradt A, et al. Bioleaching of Kupferschiefer blackshale: a review including perspectives of the Ecometals project. Minerals Engineering. 20I5;75:I I6- I25. http:// dx.doi.org/10.1016/j.mineng.2014.09.015.

6 Giaveno MA, Urbieta MS, Donati E. Mechanisms of bioleaching: basic understanding and possible industrial applications. In: Sobral LGS, Oliveira DM, Souza CEG. Biohydrometallurgical processes: a practical approach. Rio de Janeiro: CETEM/MCTI; 20II. p. 27-38.

7 Watling HR. The bioleaching of sulphide minerals with emphasis on copper sulphides: a review. Hydrometallurgy. 2006;84(I-2):8I-108. http://dx.doi.org/I0.10I6/j.hydromet.2006.05.00I.

8 Dresher WH. Producing copper nature's way: bioleaching. In: Innovations. Copper applications in mining \& extraction. Copper Development Association Inc; 2004 [acesso em 28 jan 2016]. Disponível em: http://www. copper.org/publications/newsletters/innovations/2004/05/producing_copper_natures_way_bioleaching.html

9 Brandl H. Microbial leaching of metals. In: Rehm HJ, Reed G. Biotechnology set. 2. ed. Willey Online Library; 2008. p. 191-224.

10 Ehrlich HL. Beginnings of rational bioleaching and highlights in the development of biohydrometallurgy: a brief history. The European Journal of Mineral Processing and Environmental Protection. 2004;4(2): 102-I I 2.

I I Zimmerley SR, Wilson DG, Prater JD. inventores; Kennecott Copper Corp., cessionário. Cyclic leaching process employing iron oxidizing bacteria. United States patent US 2829964. 1985 Aug 8.

12 Gehrke T, Telegdi J, Thierry D, Sand W. Importance of extracellular polymeric substances from Thiobacillus ferrooxidants for bioleaching. Applied and Environmental Microbiology. 1998;64(7):2743-2747. PMid:9647862.

13 Crundwell FK. How do bacteria interact with minerals? Hydrometallurgy. 2003;7I(I):75-8I. http://dx.doi. org/10.1016/S0304-386X(03)00175-0.

14 Rawlings DE. Microbially assisted dissolution of minerals and its use in the mining industry. Pure and Applied Chemistry. 2004;76(4):37-46. http://dx.doi.org/I0.135I/pac200476040847.

I5 Sand W, Gehrke T. Extracellular polymeric substances mediate bioleaching/biocorrosion via interfacial processes involving iron (III) ions and acidophilic bacteria. Research in Microbiology. 2006;157(I):49-56. PMid: I643 I 087. http://dx.doi.org/10.1016/j.resmic.2005.07.012.

16 Giese EC. Biofilmes: a interação micro-organismo/substrato mineral na biolixiviação. Rio de Janeiro: CETEM/MCTI; 2014. (Série Tecnologia Ambiental).

17 Rohwerder T, Gehrke T, Kinzler K, Sand W. Bioleaching review part A: progress in bioleaching: fundamentals and mechanisms of bacterial metal sulfide oxidation. Applied Microbiology and Biotechnology. 2003;63(3):239-248. PMid: 14566432. http://dx.doi.org/I0.1007/s00253-003-I448-7.

18 Mishra D, Kim D-J, Ahn J-G, Rhee Y-R. Bioleaching: a microbial process of metal recovery: a review. Metals and Materials International. 2005; I (3):249-256. http://dx.doi.org/I0.1007/BF03027450.

19 Pradhan N, Nathsarma KC, Rao SK, Sukla LB, Mishra BK. Heap bioleaching of chalcopyrite: a review. Minerals Engineering. 2008;2I(5):355-365. http://dx.doi.org/I0.10I6/j.mineng.2007.10.0I8.

20 MINTEK [página da internet]. África do Sul: ABC Live [acesso em 05 abr. 2016]. Disponível em: http://www.mintek. co.za/technical-divisions/biotechnology-bio/services-facilities/agitated-tank-bioleaching/

2I Nikolaevna KL, Sergeevich GM, Aleksandrovich RD, Vladimirovich AE, Vladislavovich RP. Method to extract metals from sulphide mineral raw materials. Russia patent RU 0002468098. 2012 Nov 27.

22 Vladimirovich AE, Nikolaevna KL, Nikolaevna TO, Aleksandrovich VK, Nikolaevich TV, Ivanovna NM. Procedure for extraction of metals out of mineral raw materials. Russia patent RU 00024 I8869. 20 I I May 20.

23 Freitas JEF, Oliveira LG. A importância da prospecção para a orientação da pesquisa científica visando a inovação. Espacios. 2013;34(2):6.

24 Passos AM, Gottlieb J. China: os impactos no Brasil de um novo modelo de crescimento [página da internet]. São Paulo: 2014 [atualizada em 31 out. 20I4; acesso em 05 jun. 2016]. Disponível em: https://www.itau.com.br/ 
itaubba-pt/analises-economicas/publicacoes/macro-visao/china-os-impactos-no-brasil-de-um-novo-modelo-decrescimento.

25 Xavier CL, Yamane DF. Fluxos de comércio internacional nos setores de insumos básicos de Brasil, Rússia, Índia e China (BRIC) no período 1996-2007. Economia e Tecnologia. 20 I0;2 I ( I): I3-20.

26 Evolução da Produção Mineral Brasileira [página da internet]. IBRAM [atualizada em 0 I fev. 20I6; acesso em I3 abr. 20 I6]. Disponível em: http://www.ibram.org.br/sites// 300// 382/00006009.pdf.

27 World Bank. Global Economic Monitor Commodities [página da internet]. [acesso em I2 jan. 20I6]. Disponível em: http://databank.worldbank.org/data/reports.aspx?source=global-economic-monitor-commodities.

28 Humphries M. China's mineral industry and U.S. access to strategic and critical minerals: issues for Congress [página da internet]. CRS; 2015 [acesso em 06 jun. 2016]. Disponível em: https://www.fas.org/sgp/crs/row/R43864.pdf.

29 SNL Metals \& Mining. World exploration trends 2015 [página da internet]. SNL; 2015 [acesso em 20 maio 2016 ]. Disponível em: http://go.snl.com/rs/snlfinanciallc/images/World-Exploration-Trends-WET-Report-20 I5-EnglishUSletter.pdf.

30 Wilburn DR, Stanley KA, Karl NA. Exploration review [página da internet]. Estados Unidos: USGS; 20I4. [acesso em 20 maio 2016]. Disponível em: http://minerals.usgs.gov/minerals/mflow/exploration-20I4.pdf.

3I BioSigma extraerá cobre desde minerales de baja ley con la ayuda de bacterias [página da internet]. Chile: BioSigma; 2012 [acesso em 24 fev. 2016]. Disponível em: http://www.biosigma.cl/en/noticias/biosigma-extraera-cobre-desdeminerales-de-baja-ley-con-la-ayuda-de-bacterias/.

32 Vilcáez J, Suto K, Inoue C. Bioleaching of chalcopyrite with thermophiles: temperature-pH-ORP dependence. International Journal of Mineral Processing. 2008;88(I-2):37-44. http://dx.doi.org/ I0.1016/j.minpro.2008.06.002.

33 Dimitrakis G, Kingman S, Palade P, Atchelor A, Jones A, Wellwood Ga, Goodes Cg, Katrib J, Dodds C, inventores; Technological Resources PTY. Limited, cessionário. Heap Leaching. United States patent US 20I503374I0. 20I5 Nov 26.

34 Crundwell FK, Norton AE. inventores. Métodos de controle de processo de lixiviação de um monte, de aumento da temperatura do monte de material para lixiviação do mesmo e de determinação da configuração de monte ótima. Brasil patent BR PI03 |4355. 2005 Jul 19.

35 Rawlings E, Tributsch H, Hansford G. Reasons why Leptospirillum-ike species rather than Thiobacillus ferrooxidans are the dominant iron-oxidizing bacteria in many commercial processes for the biooxidation of pyrite and related ores. Microbiology. 1999; |45(Pt I):5- I 3. PMid: I 02067 I0. http://dx.doi.org/ I0. I099/ I 3500872- I45- I-5.

36 Nikolaevna KL, Sergeevich GM, Aleksandrovich RD, Vladimirovich AE, Vladislavovich RP. inventores. Method to extract metals from sulphide mineral raw materials. Russia patent RU 0002468098. 20I2 Nov 17.

37 Pina PS, Leão VA, Silva CA, Daman D, Frenay J. The effect of ferrous and ferric iron on sphalerite bioleaching with Acidithiobacillus sp. Minerals Engineering. 2005; I 8(5):549-55 I. http://dx.doi.org/ I 0. I0 I 6/j.mineng.2004.08.0 I I .

38 Sobral LGS, Oliveira DM, Souza, CEG, inventores; CETEM/MCTI, cessionário. Method and apparatus for bioleaching primary ores, flotation wastes and weathered ores with biological production of sulfuric acid from elemental sulfur and/or pyrite. PCT patent WO 201409409I. 2013 Dec 17.

39 Oliveira DM, Sobral LGS, Olson GJ, Olson SB. Acid leaching of a copper ore by sulphur-oxidizing microorganisms. Hydrometallurgy. 2014;147-I48:223-227. http://dx.doi.org/I0.1016/j.hydromet.2014.05.019.

40 Duyvesteyn Willem PC, Liu H. inventores; BHP Minerals INT INC, cessionário. Processo para biolixiviação com ácidos orgânicos de minérios. Brasil patent BR PI0I09182. 2003 Feb 25.

4I Bosecker K. Bioleaching: metal solubilization by microorganisms. FEMS Microbiology Reviews. 1997;20(3-4):591604. http://dx.doi.org/10.1 I I I/j. I574-6976.1997.tb00340.x.

42 Uhrie JL, Bowman G, Caro MCA, Mayta P, Hoenecke S, Chavez M. inventores; Freeport-McMoran Corporation, cessionário. Methods and systems for leaching a metal-bearing ore for the recovery of a metal value. United States patent US 20100058894. 2012 Feb 21.

43 Giese EC. Potencial biotecnológico do uso de micro-organismos imobilizados em gel de alginato de cálcio. Rio de Janeiro: CETEM/MCTI; 20I5. (Série Tecnologia Ambiental).

44. Giese EC, Vaz PM. Bioleaching of primary nickel ore using Acidithiobacillus ferrooxidans LR cells immobilized in glass beads. Orbital: the Electronic Journal of Chemistry. 2015;7(2): I91-195. 
45 Martinez Bellange PE, Parada Valdecantos PA. inventores; Biosigma S. A., cessionário. Capsules of viable biomining microorganisms, with alginate and iron ions called biosigma bioleaching seeds (BBS) and their use for inoculation of these microorganisms in bioleaching processes. PCT patent WO 20I4057443. 20I3 Oct 09.

46 Fuqua C, Parsek MR, Greenberg EP. Regulation of gene expression by cell-to-cell communication: Acyl-Homoserine Lactone Quorum Sensing. Annual Review of Genetics. 200 I;35( I):439-468. PMid: I I 700290. http://dx.doi. org/10.I |46/annurev.genet.35.102401.090913.

47 Chaiko DJ, Rocks S. inventores; FLSMIDTH A/S, Chaiko DJ, cessionários. Compositions and methods for the leaching of ores. PCT patent WO 2014105679. 2013 Dec 20.

48 Sepúlved AEM, Cortéz PAM, Abarca MAB, Valdecantos PAP, Pasilla Iglesias LM, Barreto Roa MN, inventores; Universidad de Chile, Biosigma S. A., cessionários. Method to increase the production of extracellular polymeric substances (EPS) in an Acidithiobacillus ferrooxidans culture by the inhibition of enzymes of tricarboxilic acid cycle. US 8927246. 2015 Jan 6.

Recebido em: I Ago. 2016

Aceito em: 5 Nov. 2016 